\title{
SIMULATION MODEL FOR GREENHOUSE COOLING BY USING WATER FILM OVER AN EXTERNAL SHADING CLOTH \\ El-Sheikh, I. H. ${ }^{1}$ and A. T. Taha ${ }^{2}$ \\ 1- Department of Agricultural Engineering Faculty of Agriculture, Suez Canal University, 41522 Ismailia and \\ 2- Department of Agricultural Engineering Faculty of Agriculture, El- Menoufia University, Shebin El-kom Egypt
}

\begin{abstract}
ABESTRACT
A mathematical simulation model was developed to investigate the effectiveness of using a water film flowed on a shading cloth stretched over the greenhouse cover for greenhouse cooling. The microclimatic energy balance can simply be developed to predict the air temperature inside the greenhouse. It was dependent on different sources of energy which affect the greenhouse microclimatic conditions. The output of the model are the air temperature inside the greenhouse, relative humidity of the inside air and the soil surface temperature. The model was validated experimentally for the climatic conditions of Ismailia governorate through seven nonconsecutive days during October 2008. The data was collected under different shading conditions of the greenhouse, i.e. shading with water flow, shading only, and unshading conditions. The results of simulation model were compared with the experimental results. A good agreement was found between the measured and predicted values. The obtained results also showed that the proposed model performed well and it was adequate to simulate the microclimatic conditions.
\end{abstract}

\section{INTRODUCTION}

The magnitude and frequency of high temperatures inside the greenhouses are certainly of high concern. However in warm climates these conditions can cause significant production problems, therefore particular attention for cooling alternatives is needed (Nelson, 1981). The conventional method for reducing heat flux into greenhouses is normally undertaken using a movable shading material over the roof (Al-Arifi et al., 1999). Giacomelli (2002) reported that the greenhouse shading is a procedure for cooling and reducing the amount of solar radiation reaching the plants. By reducing the solar load in the greenhouse, the air temperature difference between inside and outside becomes smaller making the absolute air temperatures inside the greenhouse closer to the outside temperatures. Furthermore, the temperature of leaf surface can be significantly reduced.

The stretching of shading material over the roof of the greenhouse during the daytime and removing it in the nighttime is an effective and economical technique for protecting greenhouse from peak summer period. The heat flux through the roof of any structure can also be decreased substantially if water is evaporated on the surface of the roof (Sodha et al., 1981). The roof surface receives maximum amount of solar radiation (about $50 \%$ of the total radiation) in the summer and hence contributes the maximum of cooling load (Sodha, 1986). Thus, evaporation of water can be 
achieved by maintaining a thin film of water over the surface of the roof. If water temperature is below that of shading material, energy is transferred from this material to the water raising the water temperature and lowering the material temperature. From an experiment by Morris et al. (1958), it was found that the internal air temperature was reduced by using a water film over the glass surface of the greenhouse due to the lowering of the temperature of the glass surface. With intermittent application of water over the greenhouse covered externally by shading cloth, the greenhouse air temperature was reduced by $41 \%$ under wet cloth as compared with only $18 \%$ under dry cloth. (Willits and Peet, 2000). Also, Sutar and Tiwari (1995) studied the effect of water flow over the roof of an even span greenhouse covered by polyethylene cloth on the plant and air temperature. They found that the internal air temperature was $4-5 \stackrel{\circ}{\circ}$ below the control greenhouse. However, when the water was applied over the shading cloth the internal air temperature was further dropped $10^{\circ} \mathrm{C}$ as compared with the control greenhouse. Moreover, Giacomelli and Roberts (1989) used a shading blanket made of a white, woven polyester cloth of $55 \%$ shade and wetted by high pressure nozzles mounted on PVC pipe. The temperature reduction was 5-6 ${ }^{\circ} \mathrm{C}$ below the control greenhouse. Also, Mannan and Cheema (1981) sprayed water over the inclined roof of a $14 \mathrm{~m}^{2}$ glasshouse through a horizontal pipe running along the length of the roof. The inside temperature of the roof was found to be $10 \stackrel{\circ}{\circ}$ lower than the control glasshouse. Furthermore, Sodha et al. (1980) studied the reduction of heat flux by applying water flow over an insulated roof. They found that, as the flow velocity increases, the heat flux coming into the room decreases while the heat taken away by the flowing water increases. They also concluded that the maintenance of a flowing water layer over an insulated roof is more effective than a roof pond system. It is also more effective to some extent than a water film sprayed over the roof.

A mathematical model was developed for flowing water film on shading cloth stretched over the roofs and south wall of an even span greenhouse. The model was validated experimentally under three conditions (i.e. shaded with water flow, shaded and unshaded conditions). Parametric studies involving the effects of flow rate of water, length of roof, relative humidity of ambient air and absorptivity of shading material on the cooling performance of greenhouse air temperature were made with the help of the model. From the results it was found that the air temperature reduced by $6{ }^{\circ} \mathrm{C}$ and $2{ }^{\circ} \mathrm{C}$ in greenhouse shaded with water flow and shaded conditions, respectively, as compared with unshaded condition (Ghosal et al., 2003).

\section{WORKING PRINCIPLE AND EXPERIMENTAL SET-UP}

Keeping the exterior surface of the greenhouse roofs and walls wet, the cooling process is based on the process of heat absorption during the evaporation of water. Water-film concept can be achieved in the greenhouse roof by using a well-knitted jute cloth over which a thin film of water is allowed to flow. Owing to the porous property of jute cloth, it behaves like a free water surface for evaporation when keeping it wet. When falls on the free water 
surface, part of the solar radiation is reflected and the rest is absorbed for evaporating water. A little part of the absorbed radiation that is transmitted to the greenhouse is sufficient for photosynthesis process of plant. Thereby, incoming heat flux into the greenhouse enclosure is restricted for rise of inside air temperature due to thermal solar radiation.

The experimental work of this study was conducted in three polyethylene greenhouses ( $a, b$ and $c)$. Each one having a gross dimensions of $3 \mathrm{~m}$ long, $2 \mathrm{~m}$ wide, and $1.75 \mathrm{~m}$ high with a net floor surface area of $6 \mathrm{~m}^{2}$. They are constructed at Agricultural Engineering Department, Faculty of Agriculture, Suez Canal University. As shown in Fig. (1), three different cover installations were tested: (a) a single cover with an external shading cloth accompanied with applying water film over the shading cloth, (b) a single cover with only external shading cloth, (c) a single cover without external shading cloth as a control one. For water distribution over the first greenhouse, a perforated PVC pipe (2 cm diameter) was located on the top of the greenhouse. Air temperature, relative humidity, solar radiation, ambient temperature and soil temperature at depth of $0.0,5.0,10,15$ and $20 \mathrm{~cm}$ were measured.

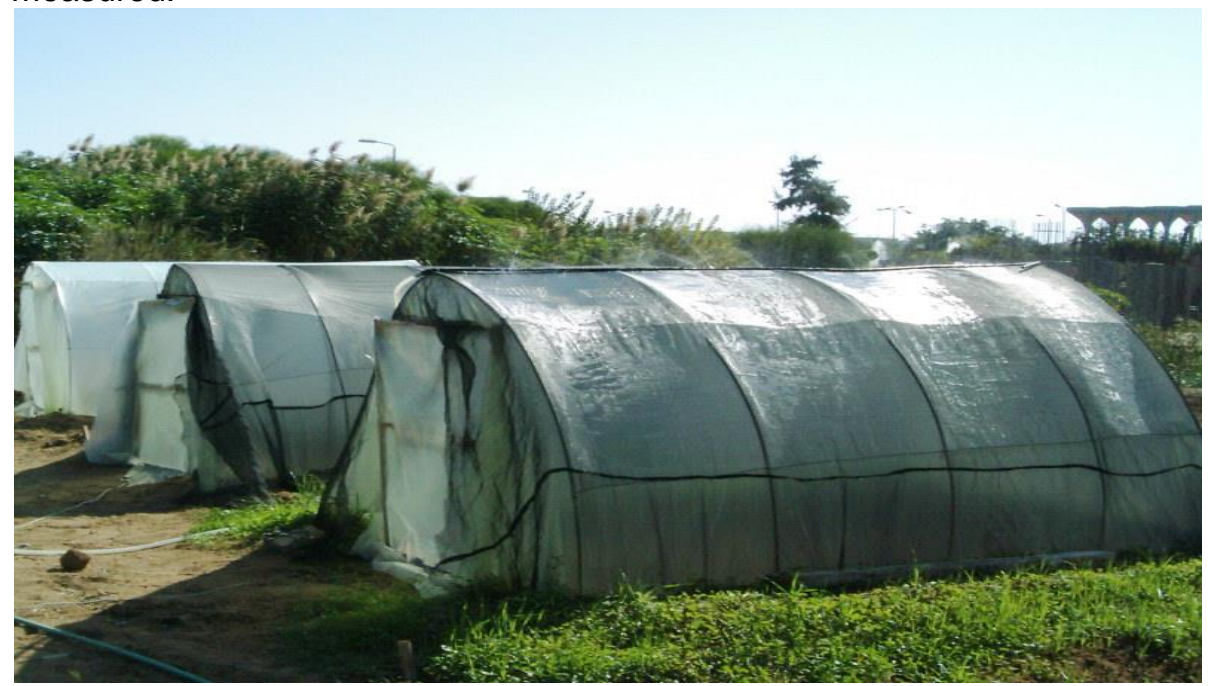

Fig. (1): Greenhouses with different shading cloth and water flow conditions.

\section{ASSUMPTIONS OF GREENHOUSE CLIMATE MODEL}

Energy balance equations for various components of the greenhouse under shading with water flow condition can be written on the basis of following assumptions: (1) analysis based on quasi-steady state condition, (2) heat capacity of flowing water is negligible for thin film in shading cloth, (3) absorptivity of water on shading cloth is the same as that of shading cloth, (4) temperature of water film, shading cloth and greenhouse cover are all the same, (5) heat conduction through the bottom layer of the ground is onedimensional, (6) convection heat transfer coefficients inside and outside the greenhouse are constant. 


\section{MATHEMATICAL MODEL}

A mathematical model of the greenhouse consisting of a set of algebraic equations was proposed. The equations were written for the three components of the greenhouse (cover, internal air and bare soil surface). The values of dimensions and material properties of the greenhouse have been substituted in these equations. The equations were solved using a computer program written in Matlab (Mathworks, MA, USA) to predict the internal air temperature, relative humidity and soil surface temperature. The output results of the computer model were then compared with the experimental results. A schematic diagram of the energy fluxes considered by this model is shown in Fig. (2)

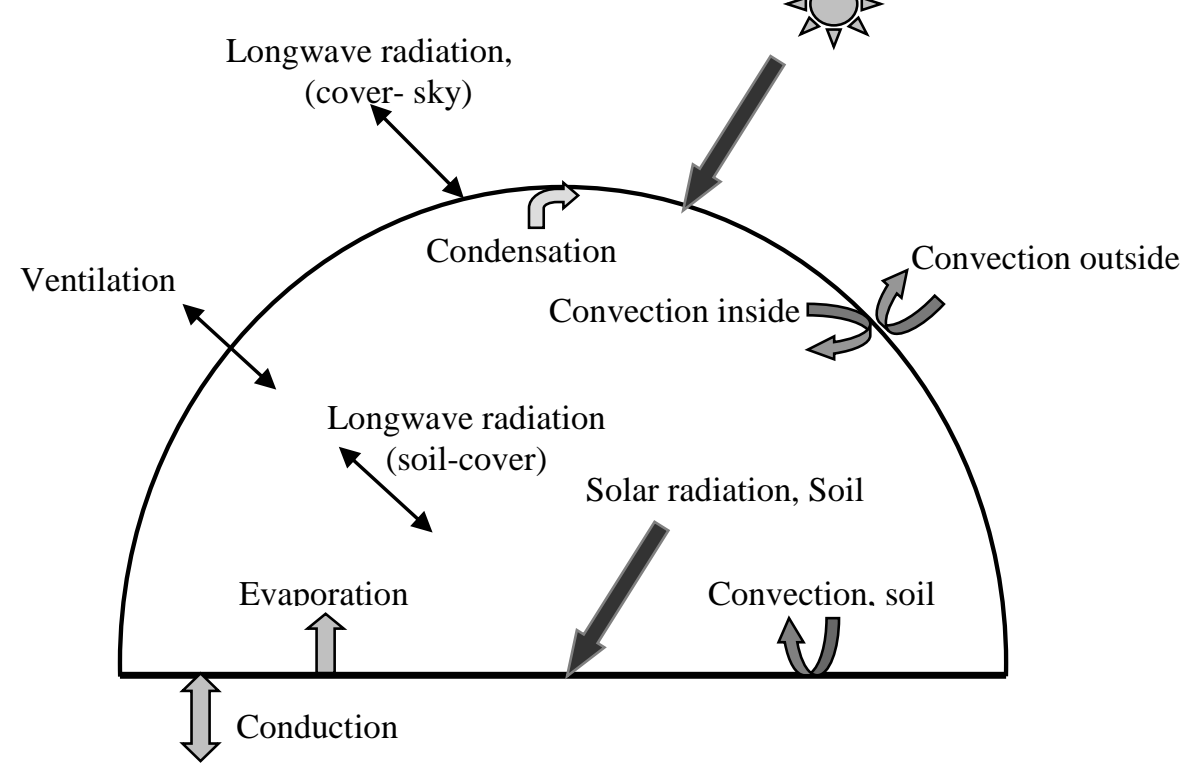

Fig. (2): Schematic illustration of the energy fluxes occurring in the greenhouse considered by the model

\section{Energy Balance on Greenhouse Cover}

Greenhouse cover is exposed to solar radiation and exchange thermal radiation with the plants, soil, and sky. Convective heat transfer takes place from the cover to the outside depending on wind speed. Condensation could also be detected on the cover depending upon the saturated humidity ratios at both the cover surface and inside air. An energy balance equation can be written for the greenhouse cover as follows (Ibrahim, 1999):-

$$
q_{c-a c c}=q_{\text {rog }}+q_{r s g}+q_{c a g}+q_{c d a g}-q_{\text {rgo }}-q_{c g o}
$$

Where:

$q_{c-a c c}=$ the heat energy accumulation in the cover, $\mathrm{W}$

$q_{\text {rog }}=$ shortwave radiant heat absorbed by the cover, $\mathrm{W}$

$q_{\text {rsg }}=$ radiant heat exchange between the soil and the cover, $\mathrm{W}$ 
$q_{c a g}=$ convective heat energy at inside cover surface, $\mathrm{W}$
$q_{c d a g}=$ heat flow due to condensation on the cover, $\mathrm{W}$
$q_{\text {rgo }}=$ longwave radiant heat emitted from the cover to the ambient air, $\mathrm{W}$
$q_{\text {cgo }}=$ convective heat at outside cover surface, $\mathrm{W}$
at energy accumulated in the cover can be computed as follows:-

vective heat at outside cover surface, W

$$
q_{c-a c c}=V_{c} C_{v g}\left(\partial T_{g} / \partial t\right)
$$

Where, $V_{c}$ and $C_{v g}$, respectively, are cover volume $\left(\mathrm{m}^{3}\right)$ and volumetric heat capacity of the cover $\left(\mathrm{Jm}^{-3} \mathrm{~K}^{-1}\right), T_{g}$ is the cover temperature $(\mathrm{K})$, and $t$ is the time (s).

The shortwave radiant heat absorbed by the cover can be determined as follows:-

$$
q_{\text {rog }}=\alpha_{s g} A_{g} I_{o}
$$

Where, $\alpha_{s g}$ is the absorptivity of the cover for shortwave (decimal), $A_{g}$ is the cover surface area $\left(\mathrm{m}^{2}\right)$, and $I_{0}$ is the solar radiation flow incident on the cover $\left(\mathrm{Wm}^{-2}\right)$.

The longwave radiant heat emitted from the cover to the ambient air can be estimated as follows:-

$$
q_{\text {rgo }}=\varepsilon_{g} \sigma A_{g}\left(T_{g}^{4}-T_{s k y}^{4}\right)
$$

Where, $\varepsilon_{g}$ is the emissivity factor of the cover (decimal), $\sigma$, is the StefanBoltzmann constant $\left(\mathrm{Wm}^{-2} \mathrm{~K}^{-4}\right)$ and $T_{\text {sky }}$, is the sky temperature $(\mathrm{K})$. The sky temperature can be calculated from the following equation:-

$$
T_{\text {sky }}=0.0552\left(T_{a o}\right)^{1.5}
$$

Where, $T_{a o}$ is the ambient air temperature $(\mathrm{K})$.

The convection heat transfer from the outside cover surface was determined as follows:-

$$
q_{\text {cgo }}=1.98\left(V^{0.8}\right) A_{g}\left(T_{g}-T_{a o}\right)
$$

Where, $V$ is the wind speed $\left(\mathrm{ms}^{-1}\right)$.

The heat flow due to condensation on the cover can be calculated from the following equation:-

$$
q_{\text {cdag }}=h_{v g i} / c_{p(a i r)} L A_{g}\left(H_{a i}-H_{g}\right)
$$

Where, $h_{v g i}$ is convective heat transfer coefficient for the internal surface of the cover $\left(\mathrm{Wm}^{-2} \mathrm{k}^{-1}\right), c_{p(\text { air })}$ is the specific heat of dry air $\left(\mathrm{Jkg}^{-1} \mathrm{k}^{-1}\right), L$ is the latent heat of vaporization of the water $\left(\mathrm{Jkg}^{-1}\right), \mathrm{H}_{a i}$ is the humidity ratio of the greenhouse air $\left(\mathrm{kg} \mathrm{kg}^{-1}\right), H_{g}$ is the humidity ratio for air at the given cover temperature $\left(\mathrm{kg} \mathrm{kg}^{-1}\right)$.

The thermal radiant heat exchange between the soil and the cover was determined using the following equation:-

$$
q_{r s g}=\varepsilon_{s} F_{s g} A_{s}\left(T_{s}^{4}-T_{g}^{4}\right)
$$

Where, $\varepsilon_{s}$ is the emissivity factor of the soil (decimal), $F_{s g}$ is the shape factor between the soil and the cover (decimal), $A_{s}$ is the soil surface area $\left(\mathrm{m}^{2}\right)$, and $T_{s}$, is the soil surface temperature $(\mathrm{K})$.

The convective heat loss from the inside cover surface was computed by the following equation:- 


\section{El-Sheikh, I. H. and A. T. Taha}

$$
q_{\text {cag }}=4.36\left(T_{a i}-T_{g}\right)^{0.25} A_{g}\left(T_{a i}-T_{g}\right)
$$

Where, $T_{a i}$ is the air temperature inside the greenhouse $(\mathrm{K})$.

\section{Energy Balance of Bare Soil Surface} surface as follows:-

An energy balance equation can be written for the bare soil

$$
q_{s-a c c}=q_{r o s}-q_{c s a}-L_{s a}-q_{r s g}-q_{d s g}
$$

Where:

$$
\begin{aligned}
& q_{s-a c c}=\text { heat energy accumulated in the soil, } \mathrm{W} \\
& q_{r o s}=\text { shortwave radiant heat by the soil, } \mathrm{W} \\
& q_{s a}=\text { convective heat transfer from the soil surface, } \mathrm{W} \\
& L_{s a}=\text { latent heat from the soil to the inside air, } \mathrm{W} \\
& q_{d s g}=\text { conductive heat transfer from the soil, } \mathrm{W}
\end{aligned}
$$

The heat energy accumulated in the soil can be computed as follows:-

$$
q_{s-a c c}=V_{s} C_{v s}\left(\partial T_{s} / \partial t\right)
$$

Where, $V_{s}$ and $C_{v s}$, respectively, are soil volume $\left(\mathrm{m}^{3}\right)$ and volumetric heat capacity of the soil $\left(\mathrm{Jm}^{-3} \mathrm{~K}^{-1}\right), T_{s}$ is the cover temperature $(\mathrm{K})$.

The shortwave radiant heat by the soil can be determined as follows:-

$$
q_{\text {ros }}=\alpha_{s}\left(1-F_{p g}\right) A_{s} \tau_{\mathrm{g}}\left(I_{o}\right)
$$

Where, $\alpha_{s}$ is the absorptivity of the soil for shortwave (decimal) ), $A_{s}$ is the soil surface area $\left(\mathrm{m}^{2}\right), F_{p g}$, is the shape factor between the plant and the cover (decimal) and, $T_{g}$, is the transmissivity of the cover (decimal).

The convective heat transfer from the soil surface can be computed as follows:-

$$
q_{s a}=2.5\left(T_{s}-T_{a i}\right)^{0.25} A_{s}\left(T_{s}-T_{a i}\right)
$$

The latent heat from the soil to the inside air is given by the following equation:-

$$
L_{s a}=h_{v s} / c_{p(a i r)} L A_{s}\left(H_{s}-H_{a i}\right)
$$

Where, $h_{v s}$ is the soil surface convective heat transfer coefficient $\left(\mathrm{Wm}^{-2} \mathrm{k}^{-1}\right)$, $H_{s}$ is the humidity ratio for air at the given soil surface temperature $\left(\mathrm{kg} \mathrm{kg}^{-1}\right)$.

The conductive heat transfer from the soil can be expressed as follows:

$$
q_{d s g}=K_{s} A_{s}\left(T_{s}-T_{b}\right) / Z
$$

Where, $K_{s}$ is the thermal conductivity of the soil $\left(\mathrm{Wm}^{-1} \mathrm{k}^{-1}\right), T_{b}$ is the soil bulk temperature $(\mathrm{K})$, and $Z$ is the thickness of the soil layer $(\mathrm{m})$.

\section{Energy Balance of Inside Air of Greenhouse}

An energy balance equation can be written for the inside air of greenhouse as follows:-

$$
q_{a i-a c c}=q_{s a}-q_{c a g}-q_{v e n}
$$

Where:

$q_{a-a c c}=$ heat energy accumulated in the inside air, $\mathrm{W}$

The heat energy accumulated in the inside air of greenhouse can be computed as follows:- 


$$
q_{a-a c c}=V_{a} C_{v a}\left(\partial T_{a i} / \partial t\right)
$$

Where, $V_{a}$ and $C_{v a}$, respectively, are greenhouse volume $\left(\mathrm{m}^{3}\right)$ and volumetric heat capacity of the air $\left(\mathrm{Jm}^{-3} \mathrm{~K}^{-1}\right)$.

The heat flow from inside to outside due to ventilation through ventilations openings (leaks and ventilation windows) can be calculated by using the following formula:-

$$
q_{v e n}=\rho v c_{p(a i r)}\left(T_{a i}-T_{a o}\right)
$$

Where, $\rho$ is the density of the air $\left(\mathrm{kgm}^{-3}\right)$ and $v$ is the ventilation rate $\left(\mathrm{m}^{3} \mathrm{~s}^{-1}\right)$.

Flow chart for solution of equations for the greenhouse model is given in Fig. (3).

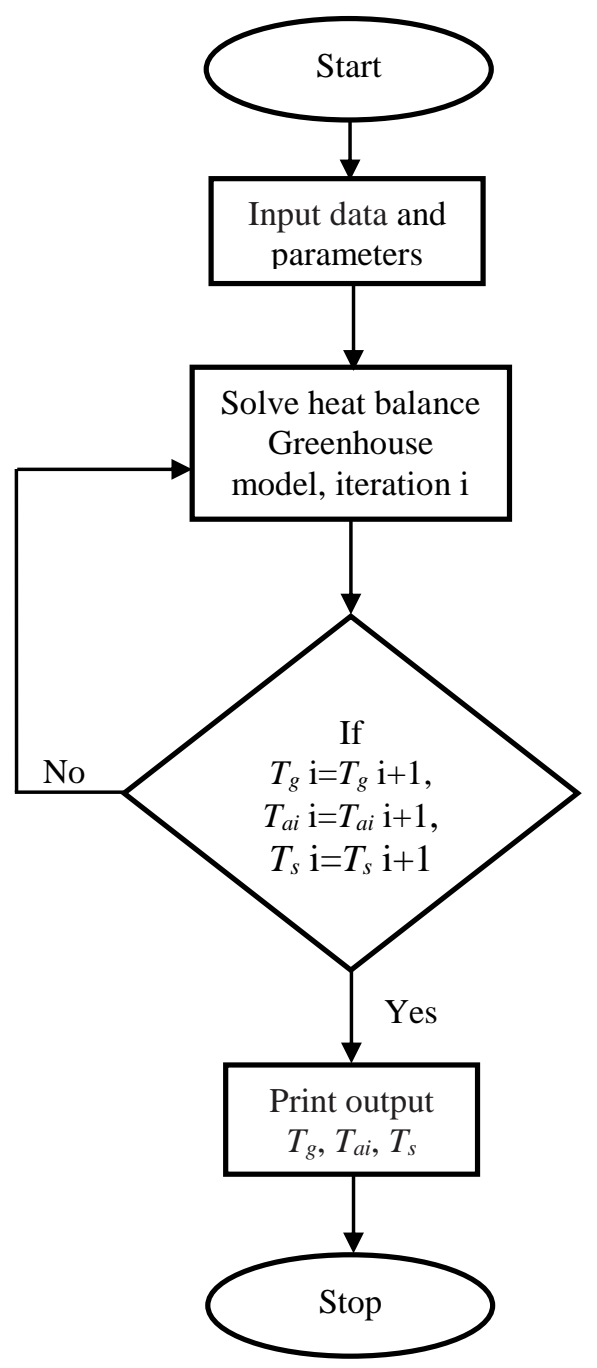

Fig. (3): Flow chart of the greenhouse model. 


\section{RESULTS AND DISCUSSION}

The equations were solved using the computer program written in Matlab software (Mathworks, MA, USA). The input parameters for the model were ambient temperature, solar radiation flux incident outside and inside the greenhouse, and relative humidity of outside air. The output of the program gave the hourly average relative humidity of the air inside the greenhouse. The predicted values of air temperature inside the greenhouses and the temperature of soil surface were also computed.

\section{Greenhouse Air Temperature}

The simplest mathematical representation of the fluctuating thermal regime in the greenhouse is assuming that the temperature oscillates as a pure harmonic (sinusoidal) function of time. The peak temperature is dampened and shifted progressively over time. The degree of damping increased in case of covered greenhouse this is related to the thermal properties of the greenhouse parts and the frequency of the temperature fluctuations. As observed in Fig. (4), temperatures were fluctuated with time which could be fitted with a sinusoidal function for the three greenhouse conditions, shaded with water flow (a), shaded (b) and unshaded (c). From this plotting, it is evidently showed that the highest peak was found in (c) with $49.1^{\circ} \mathrm{C}(322.1 \mathrm{~K})$, followed by (b) with $45.1^{\circ} \mathrm{C}(318.1 \mathrm{~K})$ and $(\mathrm{a})$ with $38.5^{\circ} \mathrm{C}$ $(311.5 \mathrm{~K})$. It is also evidently that under shading cover the temperature during daytime period decreased as compared with unshaded cover. Furthermore, cooling by moving water film over external shading black net was more effective especially on days with high solar radiation and high outside temperature. Also, it was found that the decrease in air temperature under shaded cover with water flow is more than shaded cover only.

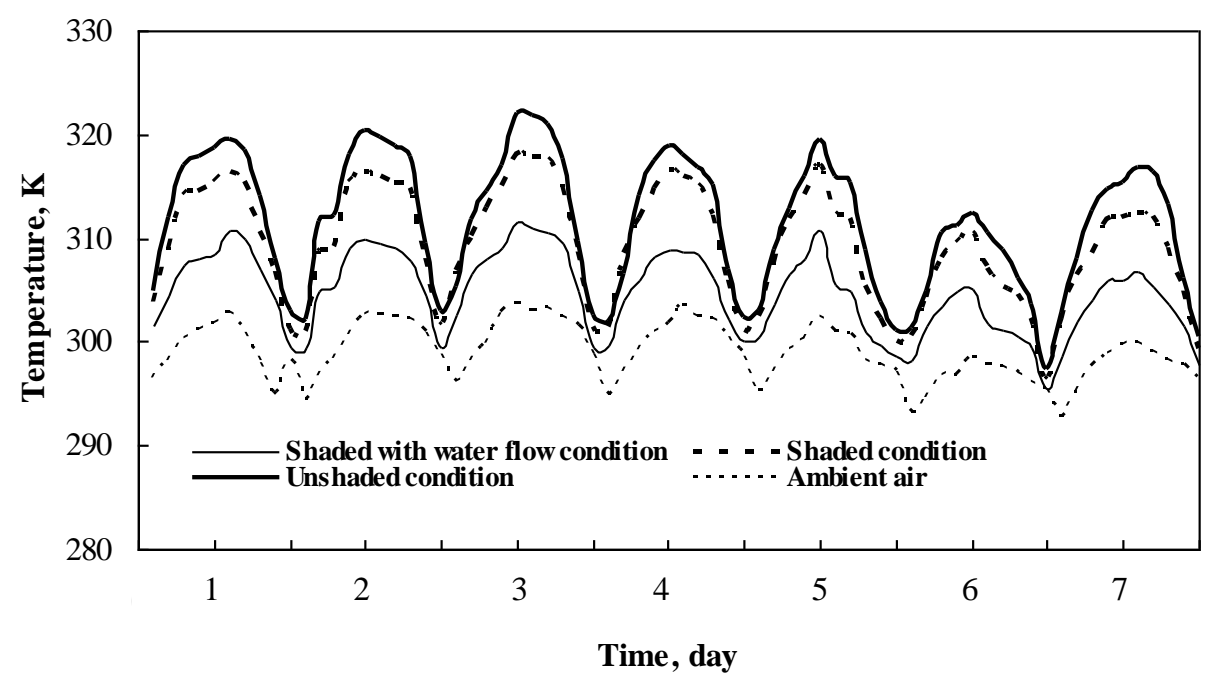

Fig. (4): Diurnal cycles of measured air temperature inside the three greenhouses and outside air temperature. 
This occurred due to the fact that the covering materials of greenhouse reflected or absorbed a part of the Near Infrared range (NIR) radiation which warms the greenhouse and crop. However, overall cooling effect was high under shading cover with water flow as compared with other two covers. According to Ghosal et al. (2003) the gain factor of heat energy is minimum under shading cover with water flow followed by shading and unshading covers. However, loss factor was high under shading cover with water flow followed by unshaded and shaded covers. Due to covering by shading black net over the roof of greenhouse the gain term was less but loss factor was found to be minimum.

Variation of the maximum temperatures on nonconsecutive days during the experimental period is represented in Fig. (5). The lowest maximum air temperature differences were 7.3 and $1.8 \mathrm{~K}$ under shading black net with water film and shading black net, respectively, as compared with unshaded cover.

Also, the highest maximum temperature differences were 10.6 and $4.0 \mathrm{~K}$ under shading black net with water film and shading black net cover, respectively, as compared with unshaded cover.

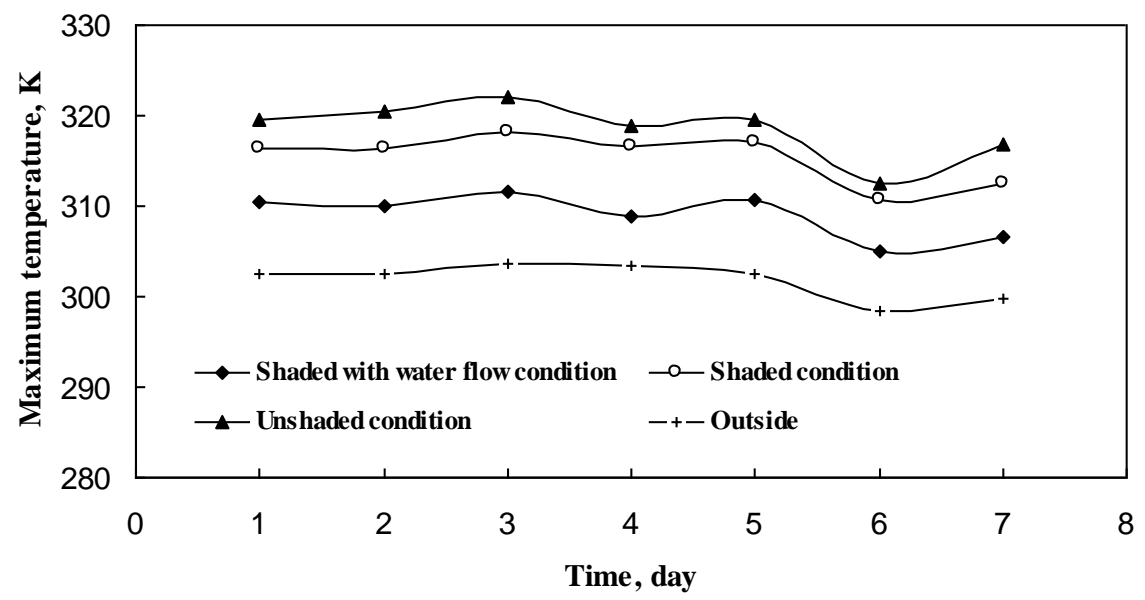

Fig. (5): Maximum air temperature variation with days.

\section{Model Evaluation}

The simulation results which obtained from this model are considered "blind", since they have not been yet compared with that measured within the greenhouse. The comparison between measured and simulated results is very important in order to check out how far the simulated results from the measured ones. It gives an idea if there are any obvious errors and prospects about the possibility of improvements that can be achieved by such model.

\subsection{Air temperature}

Air temperature in the greenhouse is considered a very important environmental parameter affecting plant growth. To investigate the model's 
ability to predict and describe greenhouse microclimatic conditions during different times, simulations were compared with that measured and recorded during 7 nonconsecutive days as follows: 16, 17, 18, 21, 23, 29 and 30 October 2008. Fig. (6) presents the measured and predicted air temperatures inside the greenhouses against simulation period assuming that the state of cover temperature equal to the simulated values obtained from the model during the simulation periods. On the sunny days, the air temperature inside greenhouses reached its peak value later in the day than the outside air temperature. As expected, this time-lag increases as the thermal mass of the areenhouse comnonents increased
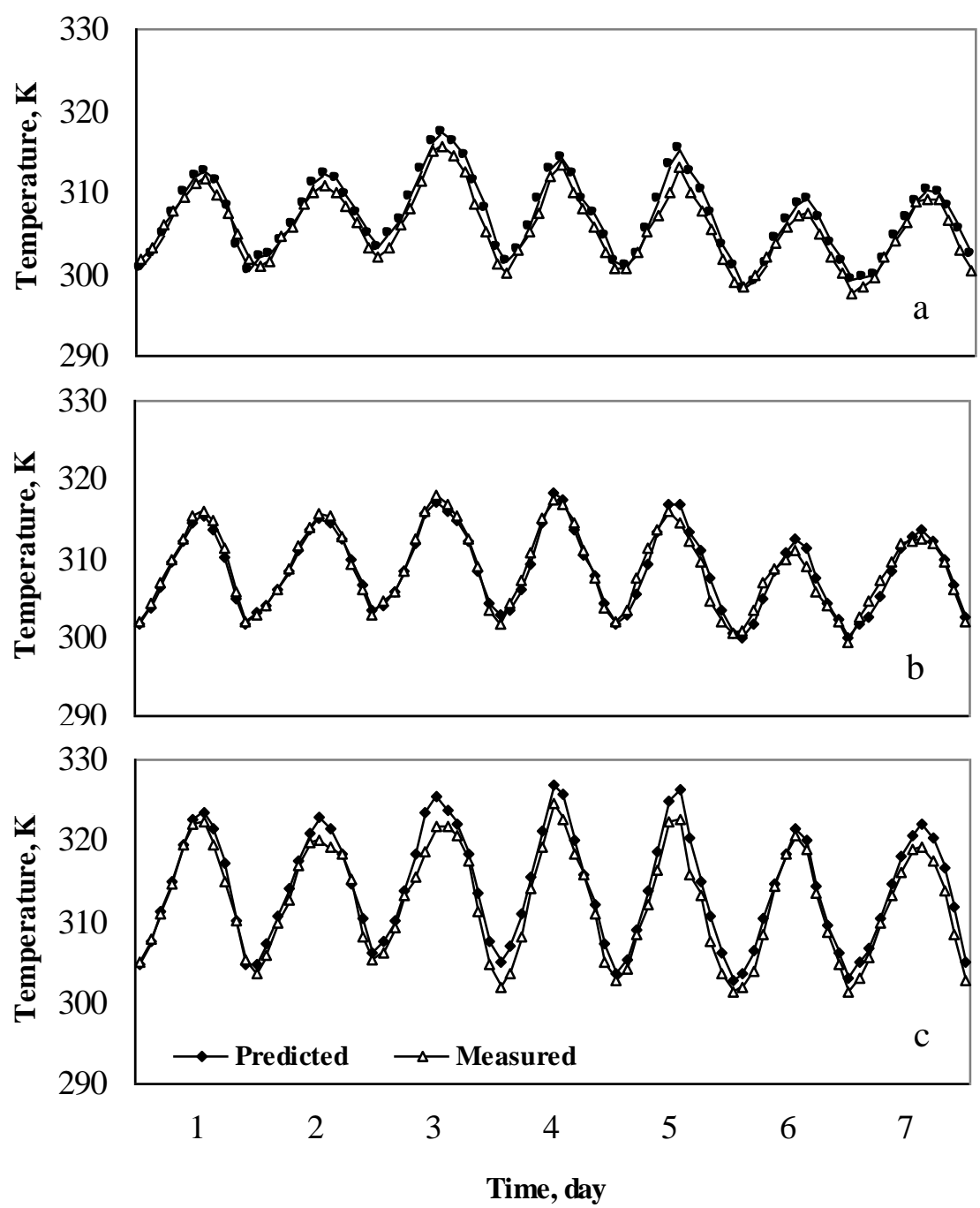

Fig. (6): Diurnal cycles of predicted and measured air temperature inside the three greenhouses in (a) shaded with water flow, (b) shaded and (c) unshaded covers. 
It can be seen that the output values obtained by simulation model is very close to the measured values. There are some differences in timing of the peak values, however this can be considered acceptable.

The measured air temperature inside the greenhouses was plotted versus the predicted temperature from simulation model as shown in Fig. (7). High correlation coefficient between the predicted and measured values was observed. The model gave accurate prediction of the air temperature inside the greenhouses. The coefficient of determination during the simulation period of seven days were $0.945,0.952$ and 0.972 for shaded with water flow, shaded and unshaded covers, respectively.

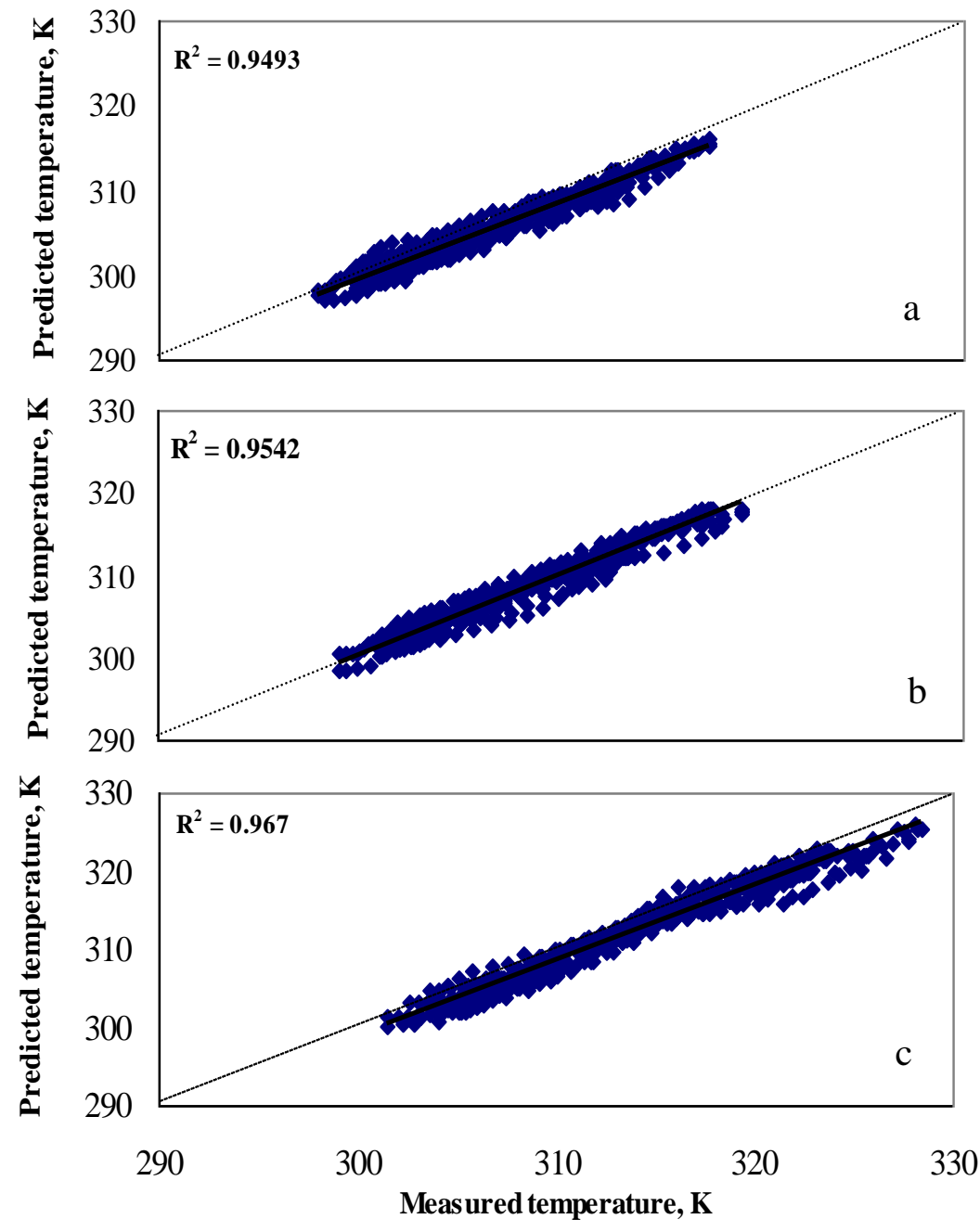

Fig. (7): Comparison between predicted and measured air temperature inside the three greenhouses for (a) shaded with water flow, (b) shaded and (c) unshaded covers. 


\subsection{Soil surface temperature}

The soil surface microclimate controls the near-surface biological processes, including seed germination, plant establishment, and microorganisms population dynamics. Soil surface microclimate characterized by soil temperature and water conditions can be altered through management. Soil temperature plays an important role in many processes, occurring in the soil such as chemical reactions and biological interactions. Soil temperature varies in response to exchange processes that take place primarily through the soil surface. These effects are distributed into the soil profile by transport processes and are influenced by different factors such as the specific heat capacity, thermal conductivity and thermal diffusivity.

The simplest mathematical representation of the fluctuating thermal regime in the soil profile is assuming that at all soil depths, the temperature oscillates as a pure harmonic (sinusoidal) function of time around an average value (Hillel, 1980). At each succeeding depth, the peak temperature is dampened and shifted progressively over time. The degree of damping increases with depth and is related to the thermal properties of the soil and the frequency of the temperature fluctuations. Plots of temperature versus time were fitted with a sinusoidal function for depths of $0.0,10$ and $15 \mathrm{~cm}$ (Fig.8). The highest peak value was found at $0.0 \mathrm{~cm}$ with $43.4^{\circ} \mathrm{C}(316.4 \mathrm{~K})$, followed by a depth of $10 \mathrm{~cm}$ with $36.6^{\circ} \mathrm{C}(309.6 \mathrm{~K})$ and $15 \mathrm{~cm}$ with $34.0^{\circ} \mathrm{C}$ $(307.0 \mathrm{~K})$ below the soil surface. At a depth more than $35 \mathrm{~cm}$ the fluctuation in temperature is neglected since the temperature remains constant throughout the experimental time. This data clearly shows how damping increases with depth.

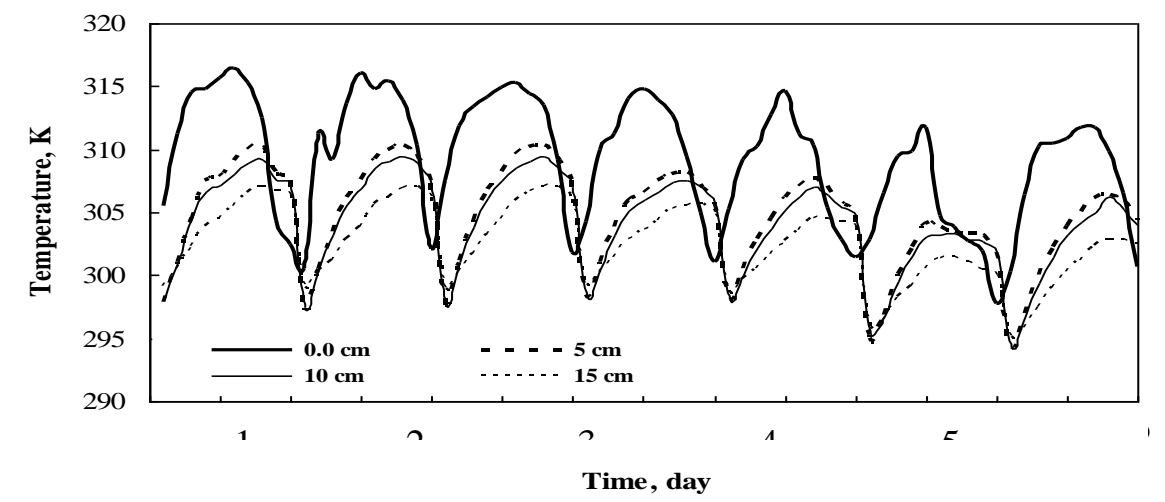

Fig. (8): Measured soil layer temperatures during the experimental period in the greenhouse of shaded with water flow cover.

Fig. (9) shows the measured and predicted soil surface temperature for seven successive sunny days. It was observed that the soil surface temperature fluctuated and increased over time with a maximum value of 54 ${ }^{\circ} \mathrm{C}(327.0 \mathrm{~K})$. This occurred due to two reasons, the first is the high solar radiation and the second is that the soil surface was influenced by the greenhouse environment. A good agreement can be observed between the 
simulated soil surface temperature and that measured. Sometimes, there are little differences between measured and predicted soil surface temperature profiles occurred. The maximum difference in the absolute temperature between the measured and predicted values was $3 \mathrm{~K}$. This difference occurred at noon each day and declined at the rest of the day.
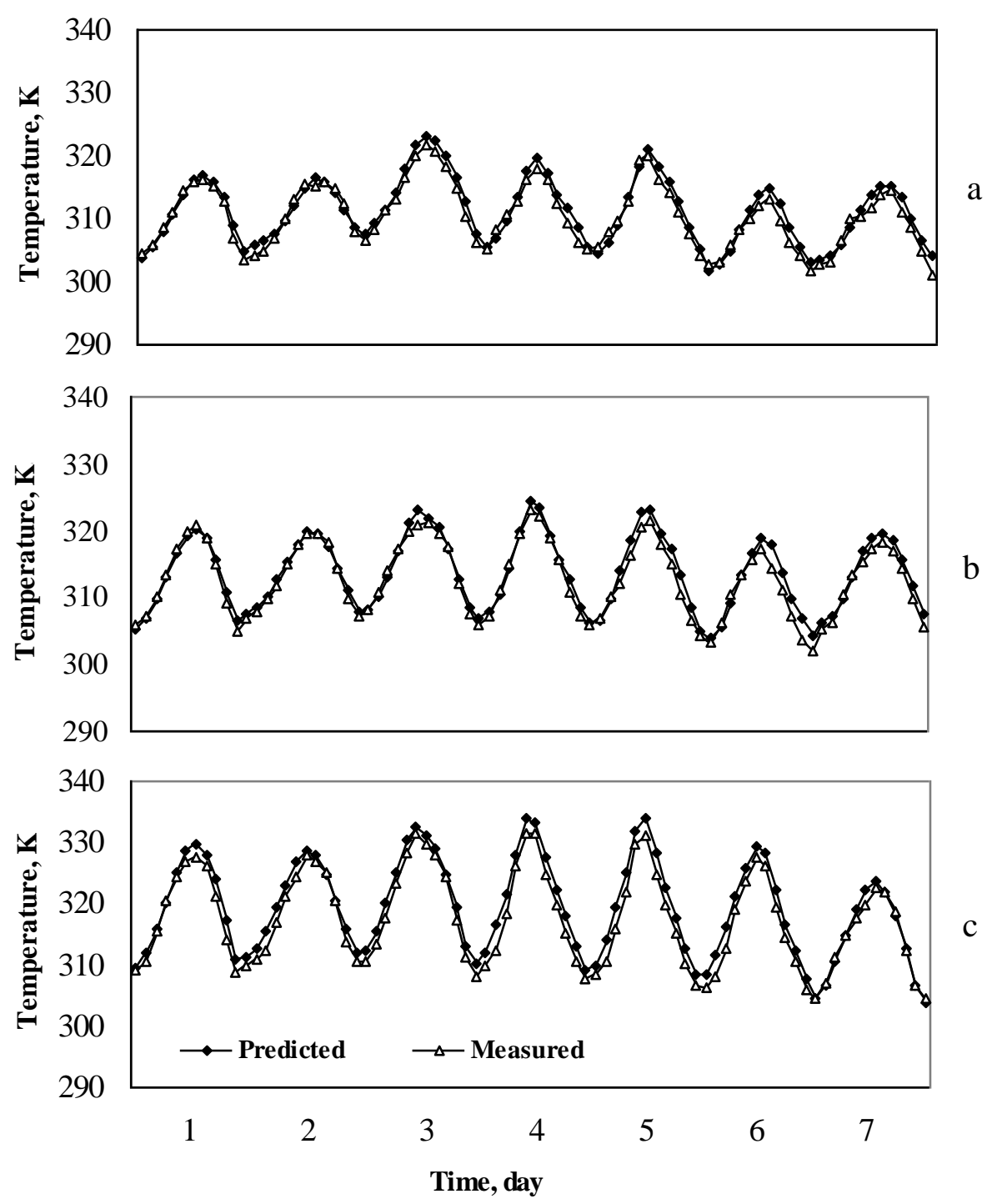

Fig. (9): Diurnal cycles of predicted and measured soil surface temperatures inside the three greenhouses during the seven days for (a) shaded with water flow, (b) shaded and (c) unshaded covers. 


\section{El-Sheikh, I. H. and A. T. Taha}

The simulation model performed well for predicting soil surface temperature as depicted in Fig. (10). The coefficient determination of soil surface temperature between predicted and measured values, respectively, were $0.944,0.957$ and 0.979 under shading with water flow, shading and unshading covers.
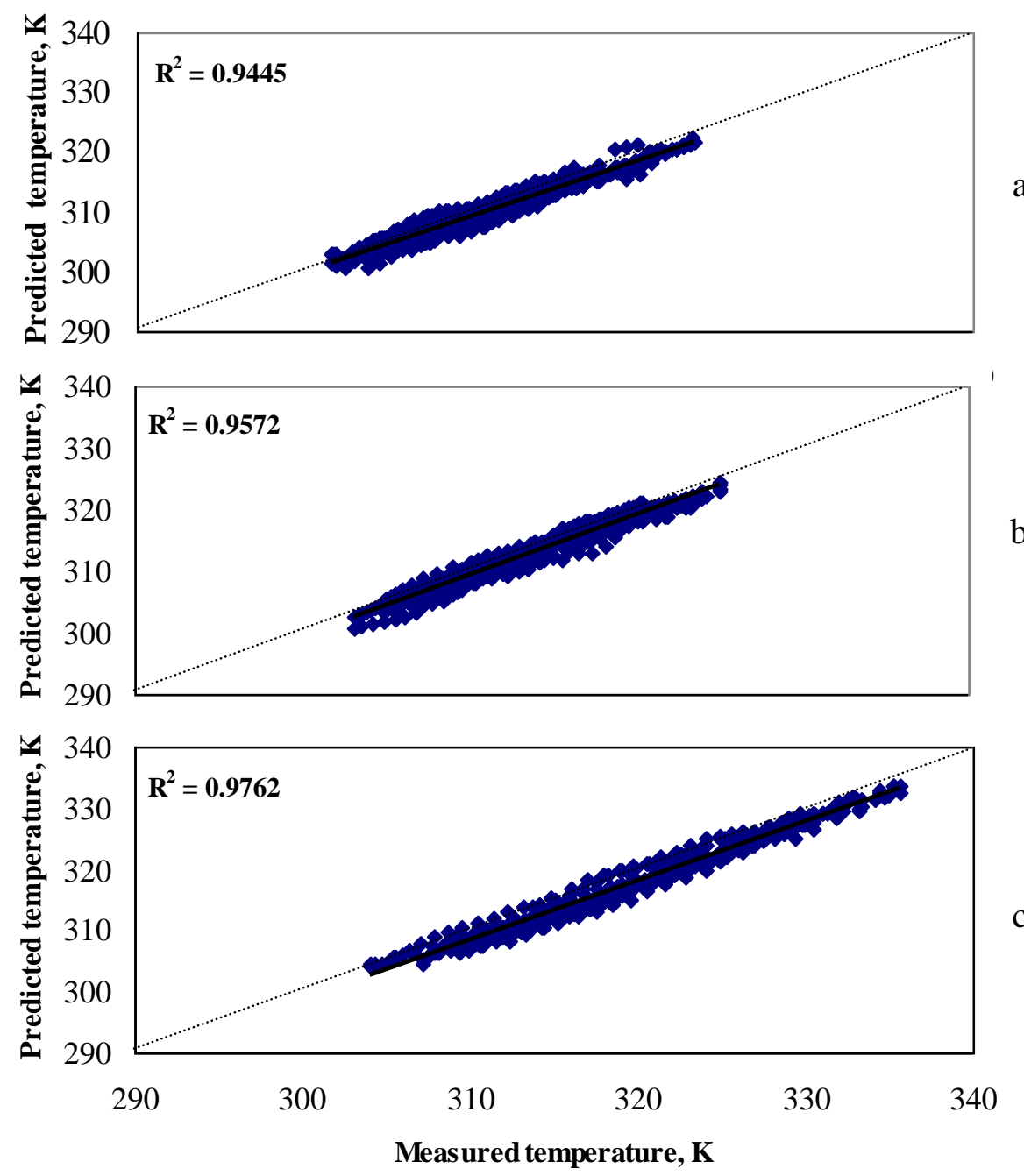

Fig. (10): Measured versus predicted soil surface temperature for the three greenhouses.

\subsubsection{Relative humidity $(\mathrm{RH})$}

The greenhouse air vapour content is necessary to describe the condensation, evaporation and transpiration, which are considered important factors for the greenhouse heat balance. Moreover, the vapour concentration 
itself is of interest because it is an important variable that controls the risk of pests and diseases. It is assumed that the sources of vapour in the vapour balance are the soil evaporation and the crop transpiration. To evaluate the simulation model for predicting the relative humidity $(\mathrm{RH})$ inside the greenhouses, the greenhouse relative humidity was measured during the same period 16, 17, 18, 21, 23, 29 and 30 October 2008. In general, a good agreement between the measured and predicted $\mathrm{RH}$ was achieved during the entire modeling period as illustrated in Fig. (11). However, in the middle of the daytime there was a little difference between the measured and predicted values.
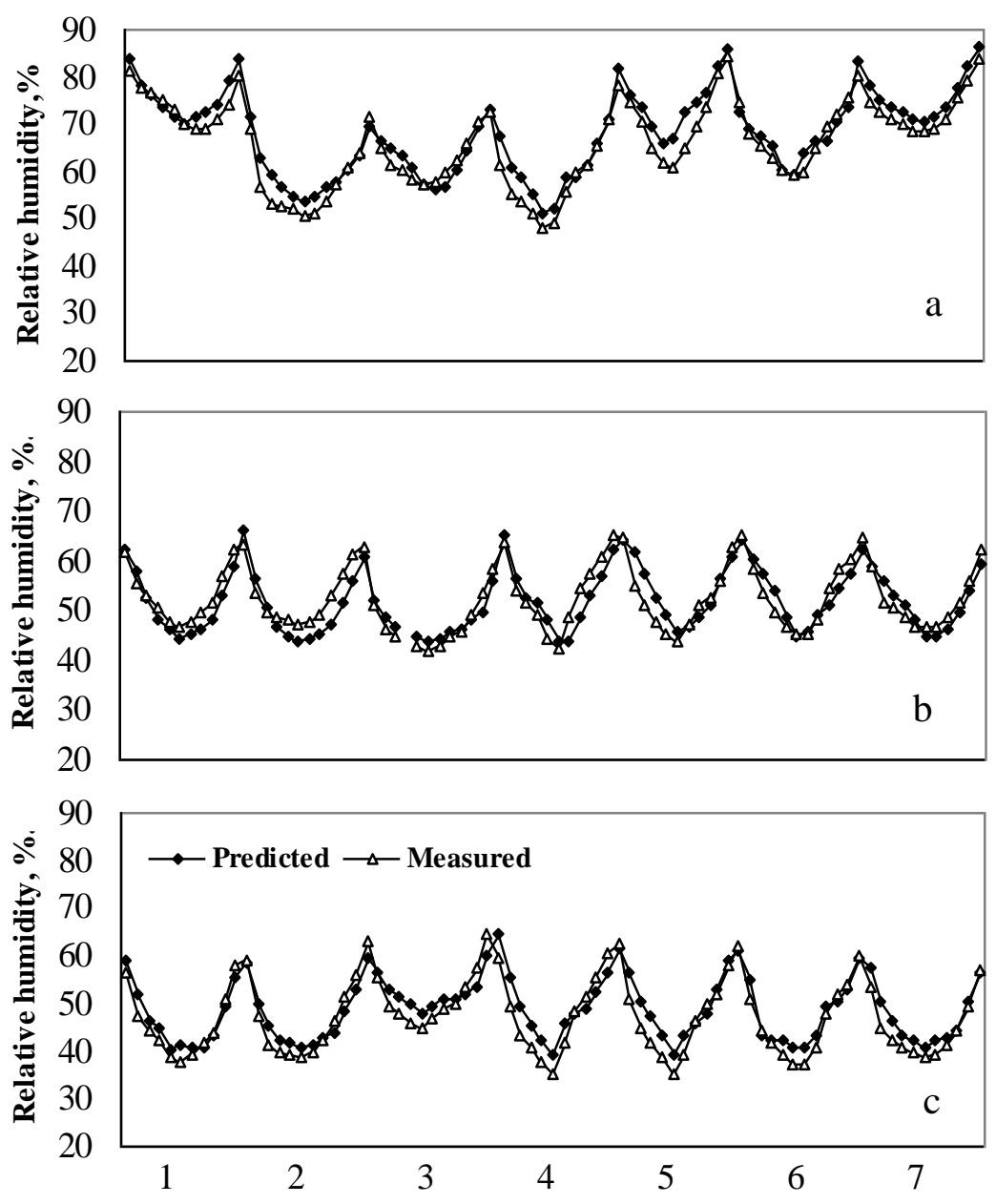

Time, day

Fig. (11): Relative humidity of air inside the three greenhouses (measured and predicted) during the period of simulation for (a) shaded with water flow, (b) shaded and (c) unshaded covers. 


\section{El-Sheikh, I. H. and A. T. Taha}

This is most likely due to the fact that more complicated energy and transfer processes exist during the daytime when the solar radiation and air exchange through the greenhouse walls and roof reached their maximum values. The model performed well for predicting relative humidity inside the greenhouse with only $10 \%$ difference from the measured values which is considered as an acceptable error (Taha, 2003).

The coefficient of determination between the measured and predicted air relative humidity inside greenhouses throughout all simulation period of seven days ranged from 0.8 to 0.91 as shown in Fig. (12).
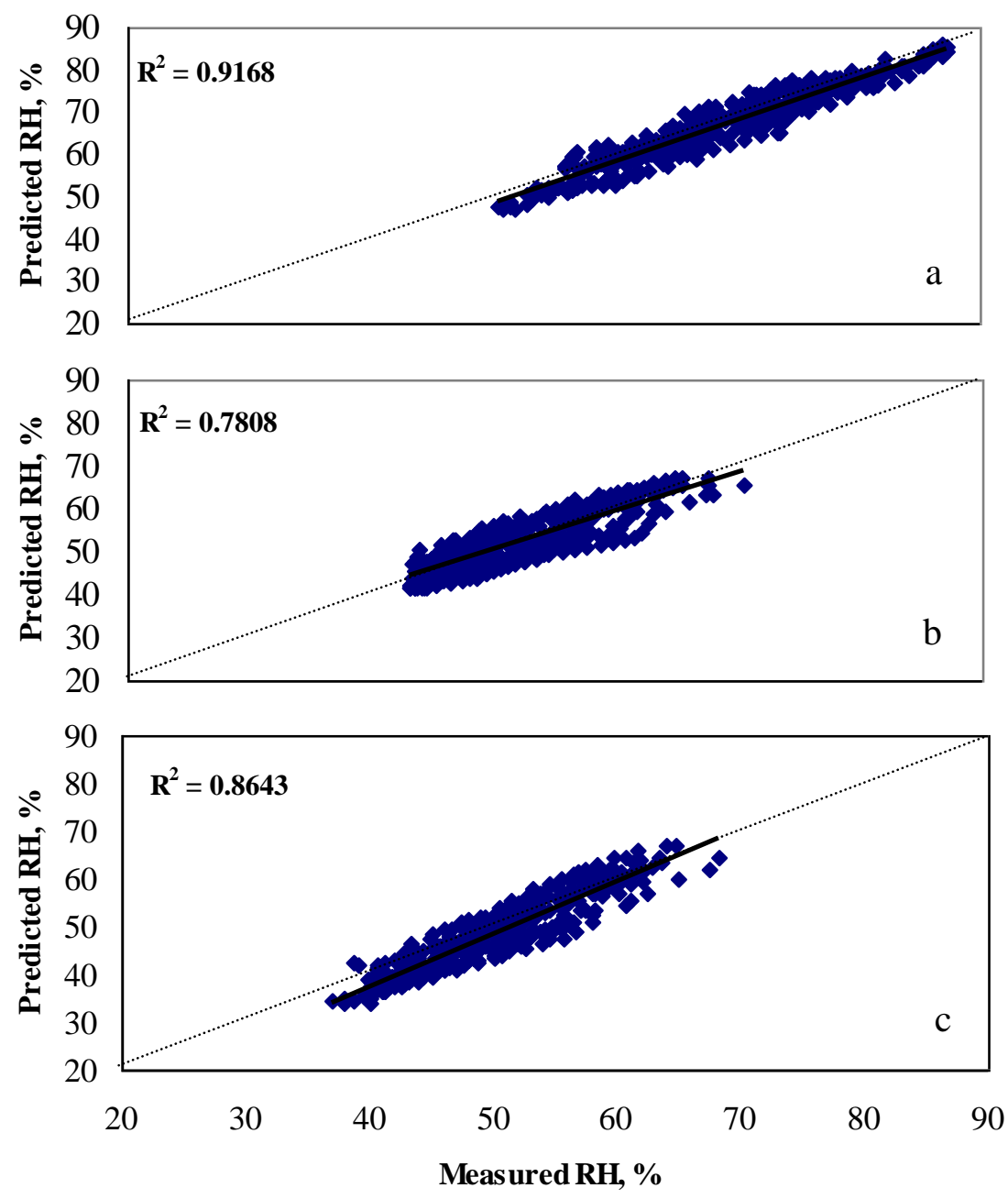

Fig. (12): Predicted air relative humidity versus measured for the three greenhouses 


\section{Conclusion}

The conclusions that can be drawn from this study are as follows:-

1- The highest maximum temperature inside the greenhouse during the experimental period is reduced by 10.6 and $4.0 \mathrm{~K}$ under shading with water flow and shading covers, respectively, as compared with unshaded covers.

2- The maximum temperature inside the greenhouse during the experimental period is increased by $7.9,14.5$, and $18.5 \mathrm{~K}$ in shading with water flow, shading and unshaded covers, respectively, as compared with outside temperature.

3- The proposed mathematical model is useful for evaluating the microclimatic conditions of greenhouse under shading with water flow over for different days which means that it is also useful for predicting the air temperature and soil temperature as well as the air relative humidity inside the greenhouse.

4- There is a good agreement between the predicted and experimental data.

\section{FUTURE EXPERIMENTAL WORK}

The obtained results of the present study revealed that to improve the model considerable attention should be given to the following points in the future experimental work:

1- The ventilation heat transfer equation in the greenhouse model should be considered.

2- Plant fluxes equations in the greenhouse model should be taken into consideration, since soil is usually partly covered by vegetation.

\section{REFERENCES}

Al-Arifi, A.; Short, T. H. and P. Ling (1999): Influence of Shading Ratio, Air Velocity and Evapotransipration on Greenhouse Microclimate, ASAE Paper no. 99-4228.

Ghosal, M. K.; Tiwari, G. N. and N. S. L. Sirivastava (2003): Modeling and experimental validation of greenhouse with evaporative cooling by moving water film over external shade cloth. Energy and Buildings 35, 843-850.

Giacomelli, G. A. (2002): Considerations for Energy Management of Greenhouse Heating and Cooling. Southern Greenhouse Vegetable Growers Association Conference, Shreveport, LA, July 19 - 20

Giacomelli, G. A. and W. Roberts (1989): Try alternative methods of evaporative cooling. Acta Horticulture 257, 29-41.

Hillel, D. (1980): Fundamentals of Soil Physics. Academic Press, New York.

Ibrahim, M. A. (1999): Predicting microclimatic conditions in greenhouses. Misr Journal of Agricultural Engineering 16, 1, 67-82.

Mannan, K. D. and L. S. Cheema (1981): Year round studies on natural cooling and heating of greenhouses in Northern India. In: Proceedings of the National Solar Energy Convention Bhavnagar, India. 
Morris, L. G.; Trickett, E. S.; Vanstone, F. H. and D. A. Wells (1958): The limitation of maximum temperature in a glasshouse by the use of a water film on the roof, Journal of Agriculture and Engineering Research, 3, 2, 121-130.

Nelson, P. V. (1981): Greenhouse operation and management (2 $2^{\text {nd }}$ Ed.). Reston Pub Co. (Prentice-Hall), Reston, VA.

Sodha, M. S. (1986): Solar Passive Building: Science and Design, Pergamon Press, New York, p. 313.

Sodha, M. S.; Govind, P. K. and S. C. Kaushik (1980): Reduction of heat flux by a flowing water layer over an insulated roof, Building and Environment, 15, 2, 133-140.

Sodha, M. S.; Kumar, A.; Tiwari, G. N. and R. C. Tyagi (1981): Simple multiple wick solar still: analysis and performance, Solar Energy 26, 127.

Sutar, R. F. and G. N. Tiwari (1995): Analytical and numerical study of a controlled-environment agricultural system for hot and dry climatic conditions. Energy and Buildings 23, 9-18.

Taha, A. T. (2003): Simulation model of energy fluxes in passive solar greenhouses with a concrete north-wall. Ph.D. Thesis, University of Hannover, Germany.

Willits, D. H. and M. M. Peet (2000): Intermittent application of water to an externally mounted greenhouse shade cloth to modify cooling performance, Transactions of the ASAE 43, 5, 1247-1252.

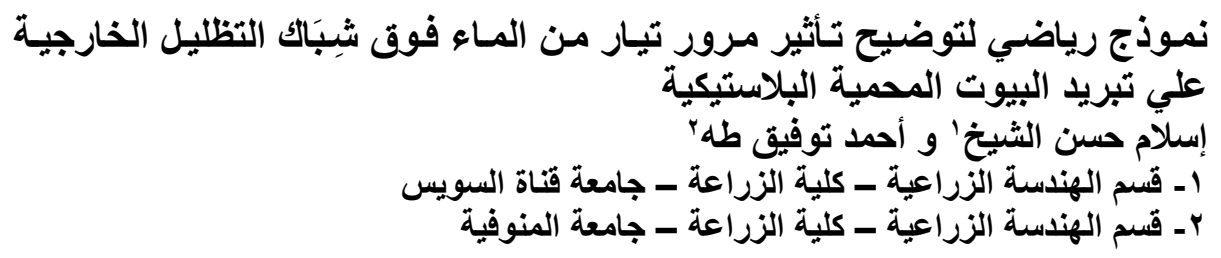




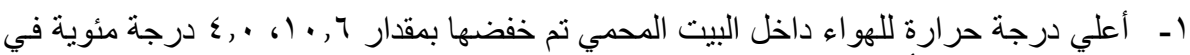

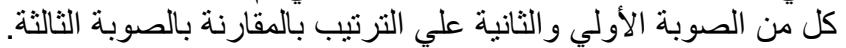

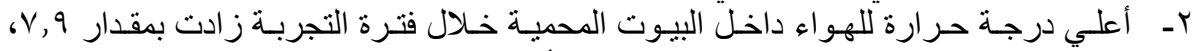

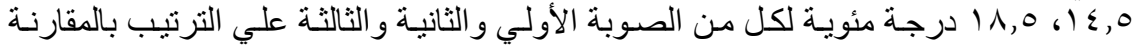
بدرجة حرارة الهو اء الخارجي.

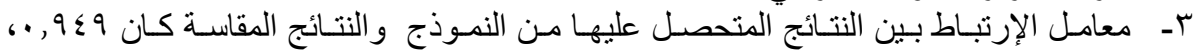

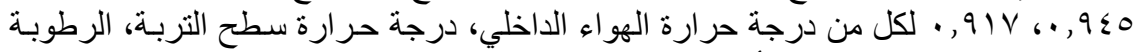

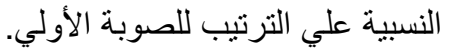

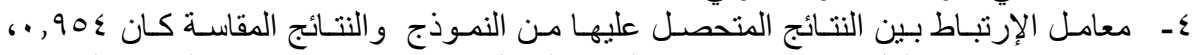

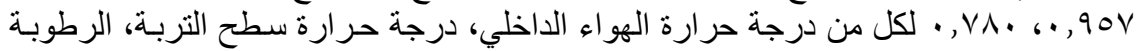

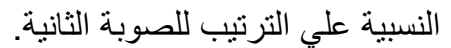

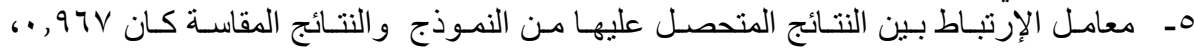

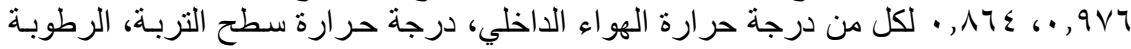
النسبية علي الترتيب للصوبة الثالثة.

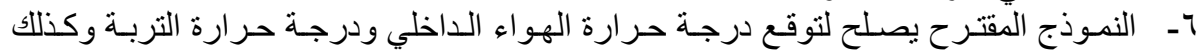

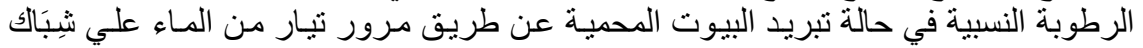
التظليل الخارجية. 